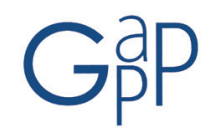

GESTIÓN Y ANÁLISIS DE POLÍTICAS PÚBLICAS, Nueva Época, nº 9 enero-junio 2013 ISSN: 1989-8991

DOI: http://dx.doi.org/10.24965/gapp.voig.10084

\title{
La población dependiente en España y su distribución por grados según el Baremo de Valoración de la Dependencia. Estimación y comparación con la población reconocida
}

\author{
Javier Rico Callado \\ Agencia Estatal de Evaluación de las Políticas Públicas y la Calidad de Servicios \\ javier.rico.callado@gmail.com \\ Recibido: 15 de junio de 3013 \\ Aceptado: 30 de julio de 2013
}

\begin{abstract}
Resumen
La población dependiente reconocida por las CCAA, así como su distribución por grados es una de las cuestiones controvertidas relativas al Sistema para la Autonomía y Atención a la Dependencia. Este trabajo analiza el volumen de dicha población en España y en las CCAA, comparándola con la población potencialmente dependiente existente. Ésta última se estima a partir del Baremo de Valoración de la Dependencia. La metodología empleada ha consistido en aplicar los criterios y normas del Baremo a la población española cuyas discapacidades se conocen a partir de los microdatos de la encuesta EDAD. Igualmente se analiza en qué grado se ha producido una sobrerrepresentación de los dependientes más severos, tanto a nivel estatal como de CCAA. Finalmente examina el efecto que sobre la población dependiente tiene el nuevo Baremo de 2011. Los resultados muestran que existe un mayor volumen de población teórica que la realmente reconocida. Ha existido sobrerrepresentación de dependientes de Grado III, tendencia que se ha atenuado con el paso del tiempo, aunque subsiste en algunas CCAA. EI nuevo Baremo no afecta a la cifra global de dependientes.
\end{abstract}

Palabras clave

Población dependiente, Baremo de Valoración, grados de dependencia, Sistema de Atención y Autonomía a la Dependencia, estimación.

\section{The Dependent Population in Spain and its Distribution by Degrees According to the Dependency Rating Scale. Estimation and Comparison with Recognized Population}

Abstract

The dependent population recognized by the Autonomous Communities and their distribution by grade is one of the controversial issues regarding Autonomy and Dependency Care System. This paper analyzes the volume of that population in Spain and the Autonomous Communities, comparing with the potentially dependent population. The latter is estimated through the Dependency Rating Scale. The research methodology used in this paper has been to apply the criteria and standards from the Scale to the Spanish population whose disabilities are known from the EDAD survey microdata. It also analyzes to what extent there has been an overrepresentation of more severe dependent, both at national and regional levels. Finally it examines the effect that the new Rating Scale of 2011 has on the dependent population. The results show that there is a greater volume of population than the one recognized by spanish authorities. There has been dependent overrepresentation of the third degree of dependency, a trend that has lessened over time, although it persists in some regions. The new Scale does not affect the overall number of dependents.

Keywords

Dependent population, Dependency Rating Scale, degrees of dependency, Autonomy and Dependency Care System, estimation. 


\section{INTRODUCCIÓN}

En el año 2007 se creó en nuestro país el Sistema para la Autonomía y Atención a la Dependencia (SAAD). Entre los factores que condicionan el coste y el correcto despliegue de la red de servicios del Sistema destacan la población en situación de dependencia, la tasa de cobertura, la intensidad protectora y el modelo de atención'.

La importancia que el volumen de la población dependiente tiene para la implantación del SAAD ha sido constatada tanto en la literatura académica como en distintas instancias decisoras. Así, el Libro Blanco de atención a las personas en situación de dependencia en España en 2005 (LB) elaborado por el IMSERSO, analizó con detalle los beneficiarios potenciales del SAAD. Este documento fue básico para el conocimiento de la situación existente y la posible configuración del futuro sistema de protección de la dependencia. La Memoria del Análisis de Impacto de la Ley 39/2006, de 14 de diciembre, de Promoción de la Autonomía Personal y Atención a las personas en situación de dependencia (LAPAD), contempló la población dependiente y la tasa de cobertura como factores de relevancia en el análisis de dicha Ley. La Memoria tomó como referencia la estimación realizada por el LB. Del mismo modo, los sucesivos Marcos de Cooperación Administrativa aprobados a partir de la entrada en vigor de la LAPAD, por los que se desarrollaba el nivel de financiación acordada, contenían la estimación de la población a atender.

Dado que la población dependiente que ingresará en el sistema es un factor de primera magnitud para garantizar la correcta implementación de la Ley y su sostenibilidad, la definición y aplicación de los criterios de elegibilidad son determinantes en la configuración del SAAD. Los criterios no sólo se configuran como auténtica vía de reconocimiento del derecho a las prestaciones contenidas en la LAPAD. También condicionan el despliegue del SAAD, puesto que el desarrollo de la cartera de servicios necesarios para la atención debe modularse en función del volumen y la distribución de la población por grados de severidad, a saber: gran dependencia (Grado III), dependencia severa (Grado II) y dependencia moderada (Grado I).

Actualmente, los criterios de elegibilidad están constituidos por un conjunto de reglas de carácter normativo recogidas en el Baremo de Valoración de la Dependencia² (BVD). En él se fijan, además, los intervalos de puntuación que corresponden a cada uno de los grados y niveles de dependencia, así como los protocolos de procedimientos y técnicas que deben seguirse para la valoración de la dependencia. Niveles que fueron suprimidos por el Real Decreto-ley 20/2012, de 13 de julio, fecha a partir de la cual tan sólo se reconocen grados.

En los años transcurridos entre la entrada en vigor de la Ley y la actualidad, la población que ha accedido al Sistema, su distribución por grados de severidad, y la aplicación del BVD por parte de las Comunidades Autónomas (CCAA), no ha estado exento de polémica. Así, a título ejemplificativo, AEVAL (2009) y el Grupo de Expertos (2009) señalaron las desviaciones en el volumen total y su distribución por grados. En todo caso, el hecho de que la LAPAD estableciese un calendario de aplicación, en el que la incorporación al SAAD de los distintos grados y niveles debía abarcar el período comprendido entre el año 2007 y 2014, desvirtuaba tanto el volumen de población como su distribución. También se ha destacado que determinadas CCAA han podido restringir el acceso a potenciales beneficiarios del sistema (Asociación Estatal de Directoras y Gerentes de Servicios Sociales, 2011), bien por déficits en las infraestructuras precisas para el pleno despliegue del SAAD, por los posibles incentivos/desincentivos de los mecanismos de financiación o por otras causas.

El presente trabajo tiene como objetivo estimar el volumen de población potencialmente dependiente en España, así como su distribución por grados de severidad, utilizando las reglas de elegibilidad del BVD. Para ello se aplicarán de forma fidedigna el conjunto de reglas y criterios contenidos en dicho Baremo a la población española, cuya estructura de discapacidad para la realización de las actividades básicas e instrumentales de la vida diaria se conoce gracias a la encuesta EDAD.

En segundo lugar se comprobará cuál es la población efectivamente reconocida constatando si se han producido desviaciones con respecto a la población potencial. No sólo en términos absolutos, sino también según los distintos grados. La progresiva entrada en el SAAD de los diferentes grados y niveles,-y en su defecto, la existencia de dictámenes de valoración-, ofrecen hoy día una imagen más fidedigna de la distribución de la población reconocida. De este modo se constatará si han existido desviaciones en la aplicación del BVD, así como si se han podido generar distorsiones en la estructura de grados, por lo que se prestará particular atención a las posibles diferencias en función de la CCAA.

Finalmente se comprobará cómo afecta el nuevo Baremo aprobado en 2011 en cuanto al volumen de población dependiente y su distribución, en comparación con el anterior.

1 Rodríguez Cabrero, Rodríguez y J. Montserrat (2002). Se obvia la esperanza de vida sin discapacidades, factor condicionado por otros factores, de índole social y de salud pública.

2 Real Decreto 504/2007, de 20 de abril. El Baremo actualmente en vigor fue aprobado por Real Decreto 174/2011, de 11 de febrero. 


\section{LAS PROYECCIONES DE POBLACIÓN DEPENDIENTE}

La disponibilidad de encuestas y microdatos relativos a la discapacidad de la población en España ha sido esencial para efectuar estimaciones de la población dependiente. Entre ellas destaca la encuesta realizaba por el INE en 1999, sobre Discapacidad, Deficiencia y Estado de Salud (EDDES). Esta fuente de datos estadísticos reflejaba las discapacidades autopercibidas de la población para la realización de las actividades diarias, y asimismo proporcionaba microdatos de gran valor para el estudio de la realidad social y la atención de la población que presentaba discapacidades. La Encuesta de Discapacidad, Autonomía personal y situaciones de Dependencia (EDAD), realizada por el INE en 2008 ha representado igualmente un avance evidente, al introducir sustanciales mejoras para el estudio de la dependencia.

Existen dos metodologías para realizar la estimación de la población dependiente. La primera de ellas no toma como referencia los criterios de elegibilidad para acceder al SAAD. Bien porque dichas reglas no se habían establecido (se aprobaron en el año 2007), bien porque dichos criterios se pueden considerar como incompletos al excluir colectivos que bajo otras premisas se considerarían como personas dependientes. La segunda metodología emplea dichos criterios con distintos objetivos y asunciones.

Dentro del primer bloque metodológico cabe destacar, por su relevancia, la estimación llevada a cabo por el Libro Blanco. Su estimación fue básica para configurar el Sistema, y fue utilizada tanto por la Memoria de la LAPAD, como por los distintos Marcos de Cooperación Administrativa. Y ello aún cuando en el debate y aprobación de la LAPAD en sede parlamentaria se amplió la población dependiente a colectivos que presentaban dificultades para la realización de actividades instrumentales de la vida diaria (AIVD). Es obvio destacar que las desviaciones a la baja en cuanto a la cifra de población potencialmente dependiente tiene notables repercusiones en el correcto dimensionamiento de recursos económicos y estructuras precisas para la atención.

Una de las dificultades para llevar a cabo estimaciones de dependencia tomando como base datos referidos a discapacidades es, por un lado, la selección de las actividades de la vida diaria cuya realización se ve afectada por dichas discapacidades. Por otro, el grado de severidad que se debe de producir de una o varias actividades para considerar a dicha persona dependiente. $Y$ finalmente el encuadramiento del individuo, en base a los parámetros anteriores, en un determinado umbral de severidad, esto es, los diferentes grados o niveles que pueden existir de dependencia.

El Libro Blanco tomó como referencia nueve actividades básicas para la vida diaria (ABVD), siempre que existía una discapacidad severa o total. Sobre esta base se construyó un indicador sintético, donde a mayor número de actividades básicas con discapacidad, y mayor grado de dificultad, mayor puntuación se asignaba. Se estimó que dicha población sería de 1.125.000 en 2005, y de 1.246.000 en 2010.

Por su parte, G. Rodríguez Cabrero (2005) construyó un índice de gravedad exhaustivo para estimar la población dependiente. Contenía catorce actividades, entre ellas algunas AIVD. Para efectuar la estimación, las actividades se ponderaban por el grado de severidad y la prevalencia. Se construían cinco grupos en base a los porcentajes establecidos por la OMS, y se tomaba, como población dependiente, los tres grupos de mayor dependencia. Como resultado, la cifra de dependientes en 1999 era de 1.797.000 personas. Sobre esa cifra se efectuaban dos proyecciones temporales, de tal modo que en 2005 la población potencial era de 2,1 millones y en 2015 de 2,6 millones.

Otras estimaciones empleaban un GoM (Grade of Membership Model). Sobre la base de ABVD y AIVD se elaboraban tipos puros que representaban grados de pertenencia, y se establecían similitudes de cada individuo de la muestra con dichos tipos, empleando una modelización que toma como base una función de máxima verosimilitud. Empleando este modelo (D. Casado, 2007), la población dependiente mayor de 65 años ascendía a 1,282 millones.

Dentro del segundo bloque metodológico cabe citar los trabajos de I. Albarrán y P. Alonso (2009) y C. Vilaplana (2010), teniendo como objetivos la estimación de la población y su proyección de cara al futuro, así como en el primer caso determinar el coste global del cuidado. La tabla 1 refleja la población dependiente según distintas estimaciones y considerando el grado de severidad en el año 2010. 
TABLA 1. ESTIMACIONES DE LA POBLACIÓN DEPENDIENTE EN ESPAÑA, 2010

\begin{tabular}{|c|c|c|c|c|}
\hline \multirow{3}{*}{ Autor } & \multirow{3}{*}{ Total } & \multicolumn{3}{|c|}{ Grado de severidad } \\
\hline & & Moderada & Severa & Gran dependencia \\
\hline & & (Grado I) & (Grado II) & (Grado III) \\
\hline Libro Blanco & 1246000 & 602636 & 420336 & 223457 \\
\hline G. Rodríguez Cabrero Et. al.(2005) ${ }^{1}$ & 2351403 & 1345969 & 577320 & 428115 \\
\hline D. Casado ${ }^{2}$ & 1095179 & 309630 & 397857 & 387692 \\
\hline G. Rodríguez Cabrero (2004)3 & 1648907 & 746.392 & 582.269 & 320.246 \\
\hline E. Morán Aláez y G. Rodríguez Cabrero (2005) & $\begin{array}{c}1.444 .7500 \\
1.583 .234 \\
\end{array}$ & & & \\
\hline C. Vilaplana & 959272 & 401258 & 239035 & 318979 \\
\hline I. Albarrán y P. Alonso & 889662 & 430418 & 221760 & 237484 \\
\hline
\end{tabular}

Fuente: Elaboración propia

\begin{abstract}
${ }^{1}$ Se emplea la EDDES de 1999 y se hacen proyecciones para 2005 y 2015 con dos hipótesis alternativas. La cifra indicada en la tabla es la menos conservadora y se haya atribuyendo a cada año entre 2005 y 2015 el incremento lineal correspondiente a cada año.

${ }^{2}$ De la cifra se ha eliminado la dependencia moderada, para hacer la tabla equivalente en cuanto a los grados. Los resultados de Casado no son comparables, puesto que se refiere a población de más de 65 años.

3 Tanto en centros residenciales como en hogares. No se efectúa proyección a 2010, los datos corresponden al año 2000 .
\end{abstract}

\title{
3. METODOLOGÍA Y LIMITACIONES
}

Cualquier análisis de fenómenos sociales o de políticas públicas se enfrenta a evidentes limitaciones. Este trabajo no es una excepción. Los condicionantes metodológicos, derivados tanto de la disponibilidad, características y naturaleza de los datos de medición de dichos fenómenos, como de los propios instrumentos o enfoques que se adopten, deben ser tenidos en cuenta a la hora de analizar los resultados.

En el presente trabajo, la población dependiente se obtendrá aplicando las reglas de elegibilidad que determina el BVD a la población española con discapacidad, cuyas características son conocidas gracias a la disponibilidad de los microdatos correspondientes a la encuesta EDAD. Dejando a un lado la cuestión relativa a las ventajas e inconvenientes que presentan los datos de encuesta en relación a los registros administrativos ${ }^{3}$, si se pretende estimar la población dependiente para proceder a una comparación con la población reconocida, tan sólo se puede recurrir a datos primarios o datos de encuesta. Los datos de registro corresponden a población efectivamente reconocida, donde pueden tener un peso no desdeñable la composición de los órganos de valoración, el margen de apreciación que queda en manos de los valoradores, o bien a que se apliquen criterios más o más o menos restrictivos en el acceso al sistema por cuestiones económicas, políticas o administrativas.

El criterio fundamental empleado en la valoración es la capacidad de la persona para llevar a cabo por sí misma una serie de actividades, tanto básicas como instrumentales, de la vida diaria, que se descomponen a su vez en un conjunto de tareas concretas. Ambas pueden observarse en la primera columna de la tabla 6 del anexo I. El Baremo establece unos criterios de aplicabilidad en función de la edad, de tal modo que tan sólo se valoran aquellas actividades acordes con el desarrollo evolutivo y grado de madurez de la persona.

En cada una de las tareas debe identificarse el nivel de desempeño, -si la persona valorada es capaz de realizar la tarea sin el apoyo de otra persona o por el contrario necesita apoyo para su realización-, y los problemas de desempeño que se manifiestan. En el supuesto de que no pueda llevar a cabo las tareas y actividades, debe establecerse el grado de apoyo de otra persona que resulte necesario. La puntuación asignada a cada tarea debe ponderase por el coeficiente del grado de apoyo.

El BVD establece dos tablas de puntuaciones diferenciadas: si la persona valorada presenta discapacidad o dependencia exclusivamente de carácter físico, se le asignan las puntuaciones señaladas en la tabla del anexo A del

3 Para un análisis más detenido de la utilización de datos de registro en el ámbito de análisis de políticas públicas o sociales puede consultarse el seminario del Instituto de Estudios Fiscales "El papel de los registros administrativos en relación con el análisis social y económico y el desarrollo del sistema estadístico nacional”. 2006. P. P. Spector (1994) ha analizado la controversia en relación a los cuestionarios de autopercepción y determinados problemas de validez e inferencia. Véase también T. Razavi (2001). Por otro lado, algunos estudios han señalado la relevancia de los datos de encuesta en comparación con los datos de registro en algún ámbito de estudio específico. 
BVD. En el caso de personas con discapacidad intelectual, enfermedad mental o con afectaciones en su capacidad perceptivo-cognitiva, se debe aplicar, además, otra tabla específica de pesos de las tareas (anexo B). En este caso se selecciona como puntuación final aquella que resulta más beneficiosa para la persona valorada.

La determinación del grado y nivel de la dependencia de la persona valorada se obtiene a partir de la puntuación final obtenida en la aplicación del BVD de acuerdo con la escala de puntuación que figura en la tabla 2.

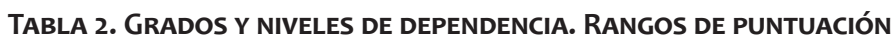

\begin{tabular}{|l|r|r|}
\hline \multicolumn{1}{|c|}{ Grado } & Nivel & \multicolumn{2}{|c|}{ Puntos } \\
\hline \multirow{2}{*}{ Grado I } & Nivel 1 & $25-39$ \\
\cline { 2 - 3 } & Nivel 2 & $40-49$ \\
\hline \multirow{2}{*}{ Grado II } & Nivel 1 & $50-64$ \\
\cline { 2 - 3 } & Nivel 2 & $65-74$ \\
\hline \multirow{2}{*}{ Grado III } & Nivel 1 & $75-89$ \\
\cline { 2 - 3 } & Nivel 2 & $90-100$ \\
\hline
\end{tabular}

Fuente: Elaboración propia a partir de la LAPAD

La metodología empleada en este trabajo para estimar la población dependiente presenta una serie de dificultades. La primera de ellas es que las respuestas a los ítems de la encuesta se basan en discapacidades autopercibidas por los encuestados. Por el contrario, la valoración real de la capacidad de la persona para llevar a cabo una serie de actividades de la vida diaria se efectúa por un equipo pluridisciplinar, mediante la aplicación de un cuestionario y la observación directa de la persona a valorar, en el entorno habitual de la persona. Además, se tienen en cuenta los informes sobre la salud de la persona y el entorno en el que viva, incluyendo las ayudas técnicas prescritas. Por otro lado se evalúa tanto su capacidad de ejecución física, como su capacidad mental y/o iniciativa.

En segundo lugar no existe una equivalencia absoluta entre las tareas y actividades definidas por el BVD y las preguntas formuladas a los encuestados 4 . De ahí que resulte imprescindible vincular con el mayor rigor posible los ítems de la encuesta con las actividades y tareas del BVD. Además, en algunas tareas, como por ejemplo aquellas comunes a la micción y defecación, se ha comprobado el grado a asociación mediante estadísticos (Phi y V de Cramer) para determinar si corresponde asignar las puntuaciones concretas de las tareas al no disponer de preguntas específicas en el cuestionario. El anexo I recoge la sistemática seguida.

En tercer lugar debe establecerse si la dependencia es consecuencia de de discapacidad intelectual, enfermedad mental o afectaciones en su capacidad perceptivo-cognitiva (DI/EM) o física, al efecto de aplicar la tabla de ponderaciones específicas. No todas las discapacidades intelectuales o enfermedades mentales propician que exista situación objetiva de dependencia, estando vinculada esta circunstancia fundamentalmente a una intensidad tal de dicha discapacidad o enfermedad que impida realizar las tareas o actividades.

Para determinar los encuestados que reúnen la condición de DI/EM se han seguido dos criterios acumulativos. Por un lado la identificación de dificultades para la realización de toda una serie de actividades que denotan un origen eminentemente mental de la discapacidad o dependencia. Tal es el caso de determinadas tareas correspondientes al aprendizaje y aplicación del conocimiento y el desarrollo de tareas, afectaciones en la capacidad perceptiva y dificultades de comunicación. La propia encuesta especifica en determinadas ocasiones que dicha dificultad debe provenir de un problema mental. Por otro lado la concurrencia de una serie de enfermedades diagnosticadas correspondientes a enfermedades y discapacidades mentales 5 . Se considera que existe DI/EM si el valor acumulado en la ponderación alcanza la puntuación de nueve. Este criterio no deja de ser discrecional. Sin embargo, parece bastante ajustado desde el punto de vista teórico, puesto que el punto de corte obliga a que el individuo acumule una serie importante de discapacidades DIEM para aplicar el anexo B. Por otro lado se han realizado distintos análisis de sensibilidad, para determinar la incidencia del criterio sobre la evolución de la población con DI/EM ${ }^{6}$. La tabla 7 del anexo I recoge las actividades consideradas.

4 La dificultad de hallar preguntas más o menos equivalentes se exacerba en el caso de las tareas relativas a la toma de decisiones en el caso de personas con discapacidad intelectual, enfermedad mental o con afectaciones en su capacidad perceptivo-cognitiva. La encuesta, en la mayoría de las ocasiones, no plantea preguntas que permitan identificar dificultades en la toma de decisiones de tareas concretas, tan sólo la imposibilidad física de llevarlas a cabo.

5 Las enfermedades contempladas en la encuesta y empleadas han sido la esclerosis múltiple, síndrome de Down, accidentes cerebrovasculares, autismo y otros trastornos asociados, parálisis cerebral, daño cerebral adquirido, demencia de tipo Alzheimer, otras demencias, esquizofrenia y trastorno bipolar.

6 Por encima de una ponderación superior a 9, no se producen importantes oscilaciones ni en la variación de población dependiente DI/EM total (más menos 11.000 en todo el rango de ponderaciones posibles) ni en la variación porcentual de la población DI/EM (que como 
Finalmente debe fijarse el grado de apoyo que necesita cada persona. La dificultad estriba en asignar la ponderación correspondiente a asistencia física máxima y asistencia especial. En el primer caso, la persona valorada requiere que otra persona le sustituya en la realización física de la actividad. Para comprobar este extremo se ha recurrido, para cada tarea concreta del BVD, a conocer el grado de dificultad que tiene el encuestado. Si éste afirma que no puede realizar la actividad, se le asigna la ponderación de asistencia física máxima.

En el caso de asistencia especial, se debe identificar si la persona valorada presenta trastornos de comportamiento y/o problemas perceptivos-cognitivos que dificultan la prestación del apoyo de otra persona en la realización de la actividad. Por ello se ha prestado especial atención al BVD con instrucciones dirigidas a los valoradores profesionales, que aporta información especialmente útil para identificar los casos. Así, no cabe recurrir a si la persona recibe actualmente apoyo, como hacen otros trabajos, puesto que éste apoyo "no debe ser interpretado en la aplicación de este baremo como que la necesidad de apoyo se encuentra cubierta (... y la prestación de apoyo de otra persona no debe considerarse como un indicio suficiente de que se necesita dicho apoyo". (IMSERSO, 2007:.8). Sino que debe utilizarse sólo en aquellos casos donde se puede identificar que "existe rechazo de ayuda o (la persona) se vuelve agresiva durante la ducha", existe sordoceguera o a través de preguntas abiertas en la entrevista y pruebas simples que identifiquen "la autonomía física mental, intelectual o sensorial" (IMSERSO, 2007:.8-9).

La mecánica seguida ha sido asignar este tipo de asistencia especial a los sordociegos y todas aquellas personas que presentaban alguna de las enfermedades mentales apuntadas anteriormente $\mathrm{y}$, al mismo tiempo, mostraban dificultades importantes que reflejan dificultades de autonomía mental o sensorial. Es el caso de la imposibilidad de mantener una conversación a través del lenguaje, prestar atención con la mirada o el oído y llevar a cabo tareas sencillas o complejas a causa de una enfermedad mental. Se trata en todo caso de un criterio notablemente restrictivo. Sólo un 7\% de la muestra reúne este requisito, porcentaje que alcanza el 17,5\% entre los dependientes. La asistencia especial así definida se concentra en los dependientes de Grado III (67\% de los casos).

Las cifras no han sido objeto de ninguna proyección temporal. A pesar de que han transcurrido tres años desde la publicación de los microdatos de la encuesta y la fecha tomada como referencia para algunos análisis del presente trabajo,-diciembre de 2011-, se parte de la presunción de que la cifra resultante es equiparable, dado que el horizonte temporal es muy escaso. Además, las proyecciones llevan implícitas la asunción de una determinada esperanza de vida sin discapacidades, difícil de determinar a medio, y fundamentalmente, largo plazo. El incremento en términos absolutos y relativos de la población de mayor edad, no tiene por qué traducirse en una mayor volumen de población dependiente, tal y como han constatado Manton, K.G., L. Corder, E. Stallard (1997) para EEUU y Jacobzone y otros (1998 y 1999) para algunos países de la OCDE. Antes al contrario, la dinámica ha sido la contraria, reduciéndose la población dependiente.

Si la cifra de población teórica estimada es una variable constante, al no efectuarse proyecciones temporales, por el contrario la población dependiente reconocida por el SAAD es dinámica, al haber evolucionado con el tiempo, tal y como se observa en el gráfico 1. Por ello en análisis de corte transversal es preciso tomar como referencia para la comparación entre ambas poblaciones una fecha determinada. Se ha optado por el mes de diciembre de 2011, considerándose que la cifra de dependientes ha alcanzado cierta madurez y estabilidad, dada la paulatina incorporación de grados y niveles al SAAD. De hecho, a partir de dicha fecha no se aprecian oscilaciones notables, ni en términos absolutos ni en los porcentajes de los distintos grados de dependencia. Por población reconocida se entiende aquella que ya haya sido valorada, aunque no reciba atención.

La comparación entre la población teórica y la reconocida puede realizarse tomando dos posibles referencias. La utilización de la totalidad de los dependientes teóricos y reconocidos ofrece una visión de conjunto de la progresiva implementación del SAAD, aunque se desvirtúan en cierto modo las desviaciones que se producen, pues no se corresponden con la progresiva entrada en el SAAD de los grados y niveles. Por el contrario, si se toma en consideración aquellos niveles de dependencia en vigor en cada momento del tiempo ${ }^{7}$, el análisis es más preciso, aunque deja fuera aquellos dependientes ya valorados que han accedido al Sistema.

Por todo lo anteriormente apuntado, las cifras absolutas de dependientes obtenidas en este análisis no tienen necesariamente que coincidir con la población reconocida. Más aún si se consideran los retos y dificultades derivados de los instrumentos basados en puntuaciones (Salvà, A. X. Rojano y T. Rivero, 2006). Pero constituyen un proxy adecuado. En otros casos, _ como por ejemplo la distribución por grados—, los datos permitirán identi-

máximo, es de $0,8 \%$ con cada incremento en tres puntos de puntuación). Igualmente se ha realizado un análisis de conglomerados por método jerárquico utilizando el algoritmo Ward, con el objeto de constatar cómo se agrupa la población discapacitada en función del conjunto de dificultades DI/EM consideradas, y contrastar que los individuos DI/EM se agrupan en los clúster de referencia.

7 Así, en 2007 estarían en vigor el Grado III, nivel 1 y 2. En 2008, junto al anterior el Grado II nivel 2. En 2009 los Grados III y II. En 2011 los anteriores y el Grado I nivel 2. A partir de 2013 la totalidad de Grados y niveles, si los dependientes ya han sido valorados. 
ficar aquellas CCAA en las que los porcentajes de dependientes por grado o nivel, son superiores a las medias para el conjunto del Estado o con respecto a la población teórica.

\section{LA POBLACIÓN DEPENDIENTE TEÓRICA Y LA RECONOCIDA EN EL SAAD}

Con la metodología apuntada anteriormente, la población dependiente asciende a 1.589.419 personas, con la distribución por grado, nivel y lugar de residencia que se indica en la tabla 3.

TABLA 3. Población DEPENDIENTE EN ESPAÑA SEGÚN BVD. EstimaCión

\begin{tabular}{|l|r|r|r|r|}
\hline \multicolumn{1}{|c|}{ Grado/nivel } & \multicolumn{1}{c|}{ Hogares } & \multicolumn{1}{c|}{ Centros } & \multicolumn{1}{c|}{ Total } & Porcentaje \\
\hline I-1 & 423.310 & 28.506 & 451.816 & \\
\hline I-2 & 214.401 & 22.151 & 236.552 & \\
\hline Total Grado I & 637.711 & 50.657 & 688.368 & $43,3 \%$ \\
\hline II-1 & 240.040 & 32.896 & 272.936 & \\
\hline II-2 & 139.273 & 23.624 & 162.897 & $27,4 \%$ \\
\hline Total Grado II & 379.313 & 56.520 & 435.833 & \\
\hline III-1 & 143.678 & 33.913 & 177.591 & $29,3 \%$ \\
\hline III2 & 215.101 & 72.526 & 287.627 & \\
\hline Total Grado III & 358.779 & 106.439 & 465.218 & \\
\hline Total dependientes & 1.375 .803 & 213.616 & 1.589 .419 & \\
\hline
\end{tabular}

Fuente: Elaboración propia a partir de microdatos de EDAD2008.

La cifra difiere de otras estimaciones efectuadas, tal y como se apreciaba en la tabla 1. Este hecho es normal, si se consideran los distintos métodos y años de referencia tomados. En particular, el LB presenta una cifra inferior de personas dependientes, aunque debe tenerse en cuenta que tan sólo incluye dependencias por ABVD .

Con el objeto de contrastar la bondad de la estimación efectuada, se han realizado distintos análisis de coherencia. En particular se ha comparado la distribución por grados, sexo y edad con otras estimaciones. Por sexo, el $33 \%$ son hombres y el $67 \%$ son mujeres. Por edad, el $24 \%$ tienen menos de 65 años, y el $73 \%$ más de 65 años. El $47 \%$ tienen edades comprendidas entre los 80 y más años. Los resultados en general, están en consonancia con otros estudios, con la excepción del Libro Blanco y R. Cabrero (2004) para la distribución por grados. Los porcentajes anteriores son prácticamente idénticos a otras estimaciones realizadas con la encuesta EDAD.

Tomando como referencia las cifras totales de dependientes, la población reconocida por el SAAD es inferior a la teórica estimada (gráfico 1) cualquiera que sea la fecha de referencia que se tome y ello a pesar de que en la literatura se ha destacado la existencia de un claro desfase entre las previsiones iniciales de la LAPAD y la realidad en cuanto al número de dependientes (AEVAL, 2009, V., D.T. Kahale Carrillo, 2009). La diferencia, no obstante, se ha ido reduciendo con el paso del tiempo. La diferencia observada en los primeros semestres tras la implantación del SAAD no es significativa, puesto que los distintos grados y niveles se incorporaban paulatinamente.

8 El LB cuantifica la población no computada como dependiente, pero con dificultades en alguna AIVD, en 746.000. De incluirse esa dificultad en la estimación, dicha cifra no se corresponde por sí misma a población dependiente, pues deben existir otras dificultades en ABVD que, acumuladas, alcancen la puntuación mínima para alcanzar el grado mínimo de dependencia. 
GRÁfico 1. Población dependiente teórica y ReCONOCIDA. AbSOLUTOS

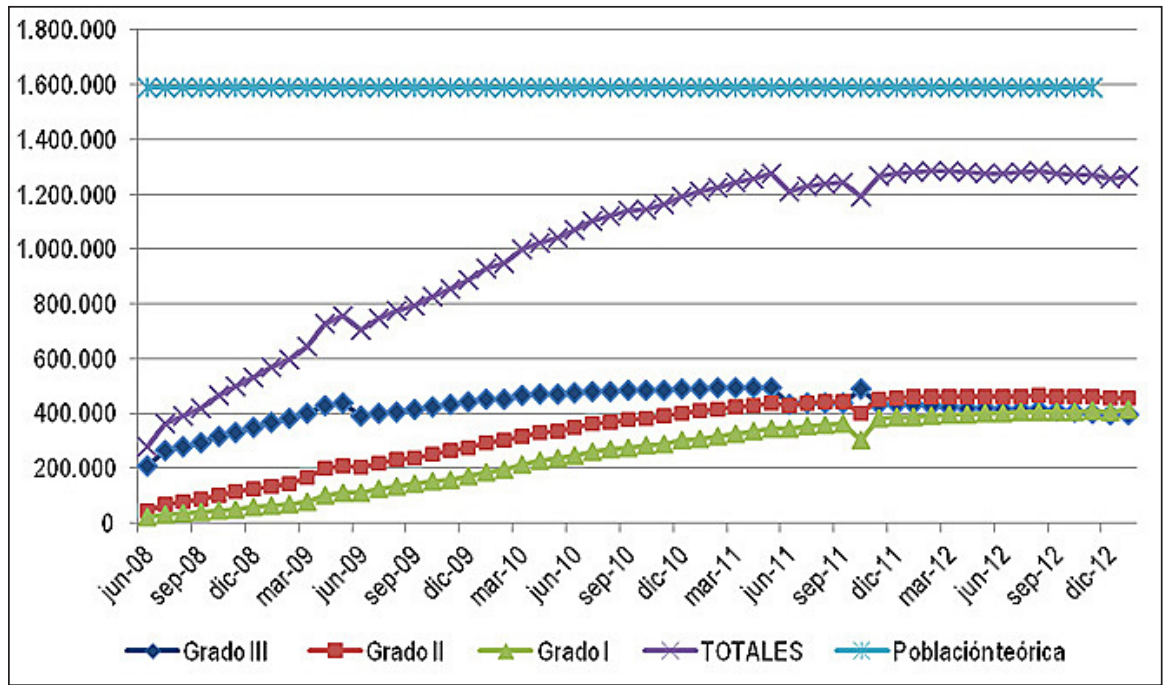

Fuente: Elaboración propia a partir de microdatos de EDAD2008 y datos estadísticos del SISAAD. Dictámenes de valoración

En la evolución de la población del SAAD se observan dos rupturas en las series, probablemente derivadas de la depuración efectuada en la cifra de población dependiente del SAAD. La distribución por grados sí ha experimentado una particular alteración, habiéndose paulatinamente reducido los dependientes de Grado III, al tiempo que se incrementan los de Grado I.

Si se toma como referencia exclusivamente los grados y niveles vigentes en cada momento, se observa (tabla 4) que la brecha existente entre población reconocida y teórica se ha ido cerrando progresivamente, gracias a la maduración del propio Sistema. En diciembre de 2010 prácticamente la totalidad de la población con dependencia había sido reconocida por el SAAD. No obstante, la desviación se amplió a partir de junio de 2011, año en el que entró en vigor el nivel 2 del Grado I, reduciéndose ligeramente a partir de dicha fecha, y ampliándose con posterioridad. Ello es debido a una reducción de la población que accede al SAAD.

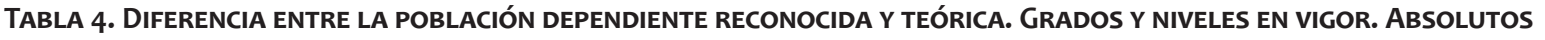

\begin{tabular}{|c|c|c|c|}
\hline \multirow{2}{*}{ Fecha } & \multirow{2}{*}{ Población reconocida } & \multicolumn{2}{|c|}{ Población teórica no reconocida } \\
\hline & & Total & Grados y niveles en vigor \\
\hline jun-08 & 277.493 & -1.311 .926 & -393.282 \\
\hline dic-08 & 532.321 & -1.057 .098 & -206.273 \\
\hline jun-09 & 704.483 & -884.936 & -307.699 \\
\hline dic-09 & 888.511 & -700.908 & -184.010 \\
\hline jun-10 & 1.067 .710 & -521.709 & -79.907 \\
\hline dic-10 & 1.189 .947 & -399.472 & -12.092 \\
\hline jun-11 & 1.208 .552 & -380.867 & -123.046 \\
\hline dic-11 & 1.273 .554 & -315.865 & -83.647 \\
\hline jun-12 & 1.276 .441 & -312.978 & -93.873 \\
\hline dic-12 & 1.257 .769 & -331.650 & -126.365 \\
\hline feb-13 & 1.257 .055 & -332.364 & -332.366 \\
\hline
\end{tabular}

Fuente: Elaboración propia a partir de microdatos de EDAD2008 y datos estadísticos del SISAAD. Dictámenes de valoración.

Por grupos etarios, la población reconocida se ajusta a la estimada, con la salvedad de las cohortes de más edad: los dependientes entre los 65 y 79, y de más de 80 años que accedieron al SAAD representan el 21\%, y el 55\%, respectivamente, si bien son el $29 \%$ y el $47 \%$ de la población teórica.

En algunos países predomina un modelo donde el internamiento en centros residenciales queda circunscrito a los casos de dependencia más severos. En nuestro caso no se disponen de datos previos y posteriores que permitan conocer si la implantación del SAAD ha provocado un efecto sustitución, de modo que las plazas en centros residenciales sean progresivamente ocupadas por dependientes, desplazando a la población más o menos válida. Ésta era, al menos, la hipótesis que se apuntaba con la entrada en vigor de la LAPAD. Sea como fuere, los resultados mues- 
tran que de la totalidad de población internada, el 26\% (77.000 personas según la encuesta) son personas teóricamente no dependientes, aunque pueden presentar algún tipo de discapacidad. Más aún, no existe prácticamente diferencia en cuanto a la distribución por grados según se resida en el hogar o en centros. Así, los dependientes de Grado III representan el $29 \%$ del total de dependientes en los centros, mientras que son el $26 \%$ en el caso de los hogares. En el caso de los dependientes de Grado I los porcentajes son del $43 \%$ y del $46 \%$ respectivamente (gráfico 2 ).

GRÁFICO 2. POBLACIÓN DEPENDIENTE TEÓRICA SEGÚN LUGAR DE RESIDENCIA.

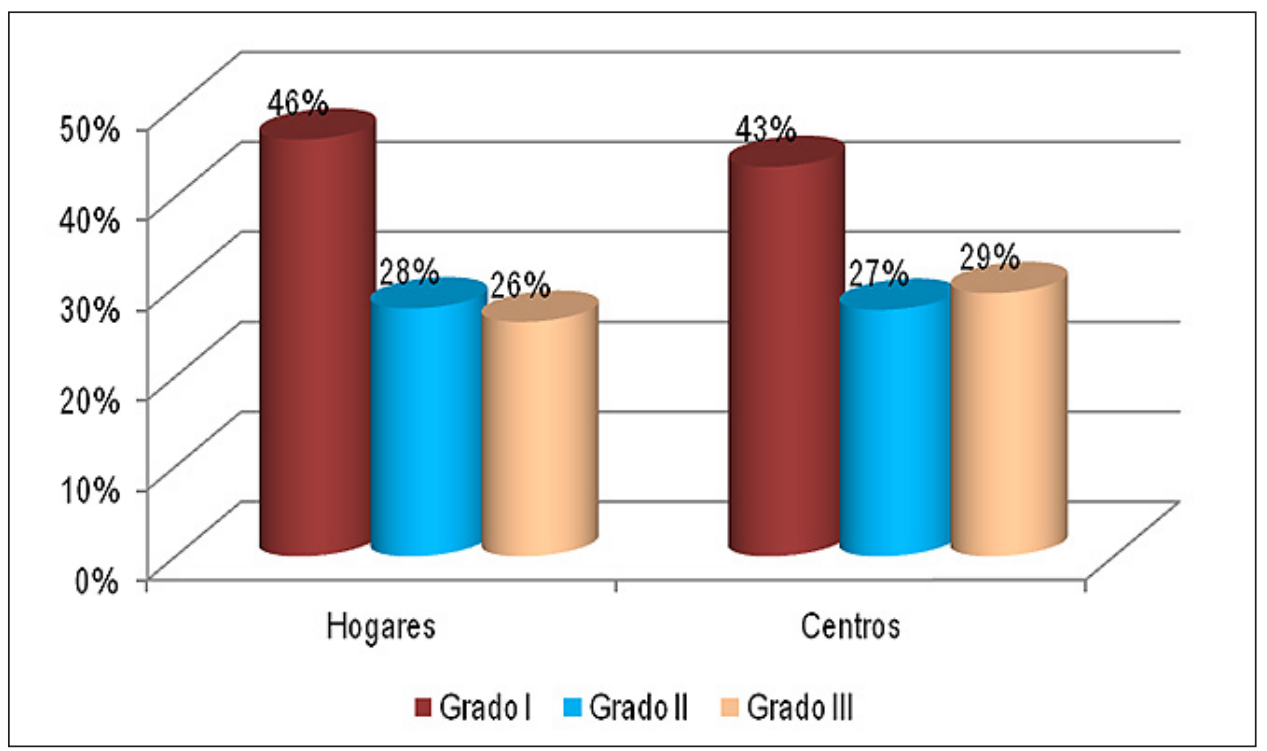

Fuente: Elaboración propia a partir de microdatos de EDAD2008.

En cuanto al comportamiento de las distintas CCAA en el acceso al SAAD (gráfico 3), se observa cómo en el caso de la Rioja, Andalucía y Cantabria, la población reconocida es superior a la estimada, tanto si se toma como referencia la población total como aquella con los grados y niveles en vigor en la fecha de referencia. Ello puede deberse a que se ha valorado en mayor grado los nuevos niveles que acceden al SAAD. Por el contrario, la mayoría de CCAA reconoce un número menor de dependientes en comparación con los teóricamente existentes. En éste último supuesto destacan la Comunitat Valenciana, Galicia, Asturias, el P. de Asturias y Canarias, con porcentajes que varían entre el -104\% (esto es, se reconoce tan sólo la mitad de los potenciales beneficiarios del sistema) y el $-76 \%$, para los totales.

\section{GRÁFICO 3. POBLACIÓN DEPENDIENTE RECONOCIDA CON RESPECTO A LA ESTIMADA POR CCAA. PORCENTAJES}

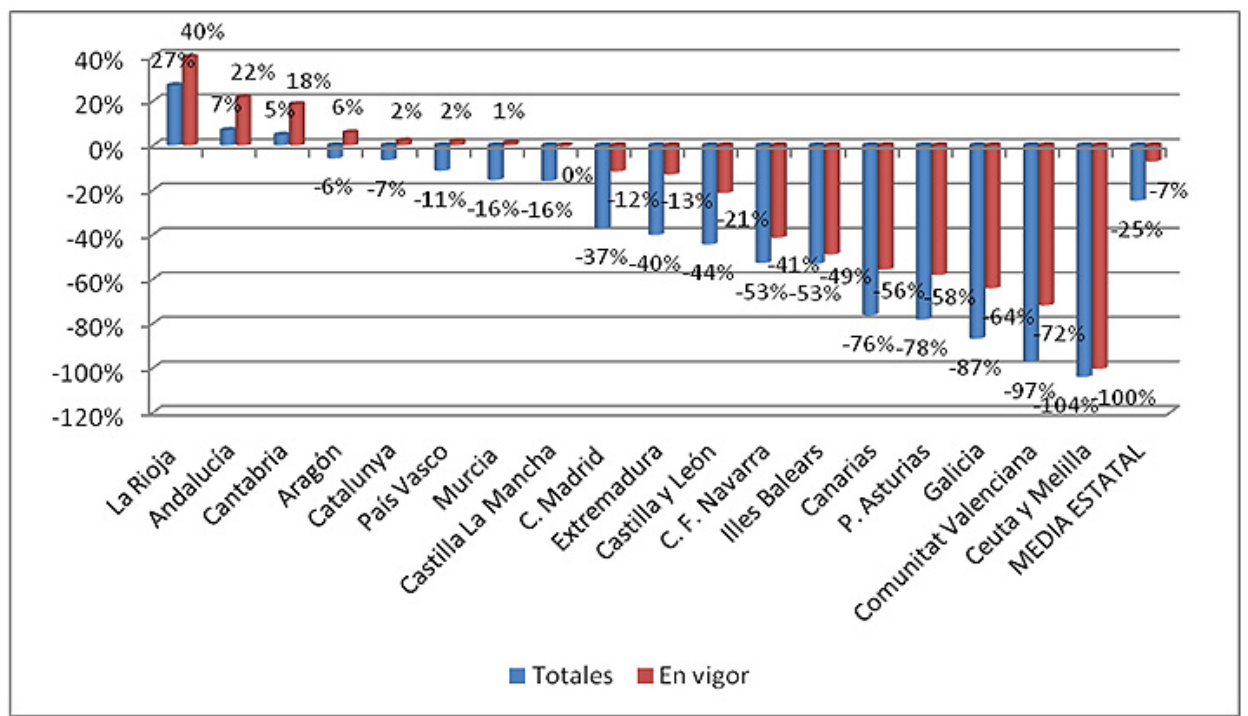

Fuente: Elaboración propia a partir de microdatos de EDAD2008 y datos estadísticos del SISAAD. Comparación referida a diciembre de 2011 


\section{LA DISTRIBUCIÓN POR GRADOS Y LA SOBRERREPRESENTACIÓN DE LOS DEPENDIENTES MÁS SEVEROS}

La distribución por grados de dependencia y la sobrerrepresentación de los dependientes más graves en el SAAD es un aspecto señalado en diferentes estudios. Un cúmulo de causas ha podido contribuir a esta sobrerrepresentación. Así, AEVAL (2009) destacó que el elevado número de grandes dependientes con respecto al LB y la Memoria Económica podría explicarse bien por una sobrerrepresentación de los dependientes de Grado III, o por la existencia de un volumen mayor de población, causado por un desfase de las previsiones iniciales. El Grupo de Expertos (2009) apuntó a unas proyecciones aparentemente bajas en cuanto al Grado III que explicaría la forma de pirámide invertida. Marbán Gallego (2012) señaló que en 2009 se habían dictaminado como dependientes de mayor grado el doble de lo proyectado por el LB.

La aplicación desigual o incluso discrecional del BVD también podría constituir un factor explicativo. La permisividad en su aplicación (A. Rodríguez Castedo y A. Jiménez Lara, 2010, entre otros), las pasarelas establecidas, la composición de los órganos de valoración o la configuración inicial del Baremo han podido contribuir a ello. El Ministerio de Sanidad (2010), también aludió a esta cuestión, señalando que la maduración del sistema comporta una aplicación más precisa del BVD, motivada por una mayor experiencia y que arroja como resultado una mayor exactitud y calidad.

AEVAL apuntó como hipótesis la existencia de incentivos/desincentivos a través de los mecanismos de financiación del SAAD. La Ley fijó un nivel mínimo de atención, cuyo pago corresponde a la Administración General del Estado (AGE). El criterio de asignación de recursos a las CCAA era capitativo, siendo la cuantía transferida por dependiente fija, según el grado y nivel de dependencia, sin vinculación con los servicios que recibiese el beneficiario. De este modo "el propio mecanismo de financiación del nivel mínimo podría estar incidiendo de alguna manera en los sesgos a favor de los reconocimientos de mayor grado y nivel posibles. Así, la existencia de un sistema de financiación capitativo (...) junto al hecho de que la cuantía aportada por la AGE difiera en función del grado y nivel de dependencia, pueden estar condicionando la estructura de reconocimiento por grados y suponer un incentivo para que las CCAA reconozcan dependientes en grado superior, obteniendo, de este modo, mayores recursos de la AGE" (AEVAL, 2009: 49). En definitiva, el sistema de financiación podría generar distorsiones, y constituir un incentivo para incrementar los dependientes de mayor severidad.

Finalmente la implantación de la Ley a distintas velocidades o la existencia de diferencias territoriales en el nivel de desarrollo del SAAD también podrían explicar la desigual distribución.

Sea como fuere, las distorsiones por grado se han ido corrigiendo, con la incorporación de los restantes grados, y con el nuevo baremo establecido. No sólo eso, sino que se ha señalado que en los últimos meses se ha "producido una revisión brutal adjudicando grados por debajo del obtenido a personas dependientes en su día con grados superiores" (Barriga Martín, L., Ma Jesús Brezmes Nieto y G. A. García Herrero, 2013). Hasta el punto en que la tasa de reposición ya no se mantiene en ningún grado.

Esta atenuación de la distribución por grados e incluso su inversión se aprecia en el gráfico 1, en términos absolutos. El porcentaje de dependientes de Grado III con respecto al total ha pasado del $75 \%$ en 2008 , al $55 \%$ en 2009, el 44\% en 2010, el 36\% en 2011 y al 32\% en 2012. Desde la entrada en vigor del nuevo BVD (febrero de 2012 ) no se ha producido una reducción significativa en dicho porcentaje, variando un $2.5 \%$.

Los datos de la estimación realizada reflejan esta sobrerrepresentación, aunque atemperada con respecto a fechas anteriores. Así, en diciembre de 2011, para el conjunto del Estado los dependientes de Grado III reconocidos en el SAAD superan en un $5 \%$ a los teóricos estimados, cifra que aumenta hasta el 9\% para el Grado II. Por el contrario la infrarrepresentación de los dependientes más leves es del 13\%.

La situación es muy disímil según el territorio (gráfico 4). En CCAA como Canarias y Castilla y León la sobrerrepresentación alcanza el 15\%, en Murcia, Galicia, Extremadura, La Rioja y la C. Valenciana rondan el 10\%. Y Madrid, Aragón, Cantabria y Andalucía oscilan entre el $6 \%$ y el $4 \%$. Por el contrario, en el País Vasco y fundamentalmente Navarra existe infrarrepresentación (del $18 \%$ en el último caso).

En definitiva, con el antiguo BVD en vigor en la fecha tomada como referencia para el análisis del presente trabajo, la práctica totalidad de las CCAA presentaban una sobrerrepresentación de los dependientes más severos con respecto a lo que les correspondería. 
GRÁFICO 4. SOBRERREPRESENTACIÓN DE POBLACIÓN CON GRADO III Y GRADO II POR CCAA. PORCENTAJES

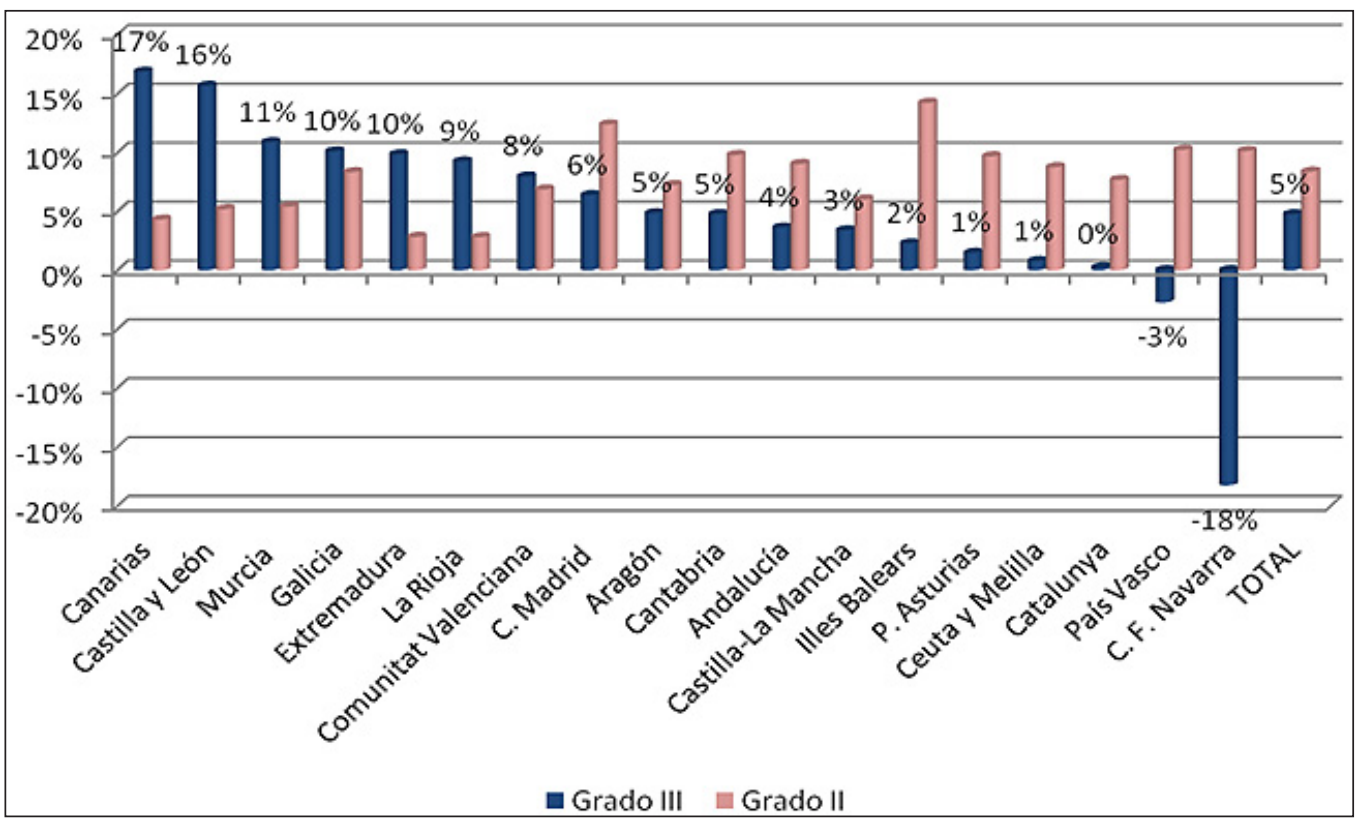

Fuente: Elaboración propia a partir de microdatos de EDAD2008 y datos estadísticos del SISAAD. Comparación referida a diciembre de 2011

Si dicha circunstancia se analiza desde el punto de vista longitudinal (la evolución en el transcurso del tiempo), se observa que la constante reducción del porcentaje de dependientes de Grado III con respecto al total, ha comportado que la sobrerrepresentación haya disminuido, situándose en un 2\% en marzo de 2013. Cifra que puede ser comprendida dentro del margen de error habida cuenta de la metodología empleada. A nivel de CCAA dicha tendencia se observa igualmente, aunque en distinta medida según la CCAA de la que se trate, tal y como se aprecia en el gráfico 5. Comunidades como Canarias (15\%), Castilla y León (11\%), Murcia (9\%), Extremadura y la Rioja (6\%) o la C. Valenciana (5\%) continúan manteniendo niveles de sobrerrepresentación destacables. Por el contrario, ninguna CCAA presenta valores inferiores al $-4 \%$.

En qué medida este hecho se deba a la paulatina maduración del sistema, o a otros factores, tales como la entrada en vigor del nuevo BVD, la adjudicación de grados por debajo del inicialmente reconocido en las revisiones efectuadas u a otros factores, es una cuestión difícil de dilucidar, a falta de estudios de casos y de otros datos relativos a la aplicación pormenorizada del BVD.

\section{GRÁFICO 5. EVOLUCIÓN DE LA SOBRERREPRESENTACIÓN DE POBLACIÓN CON GRADO III POR CCAA}

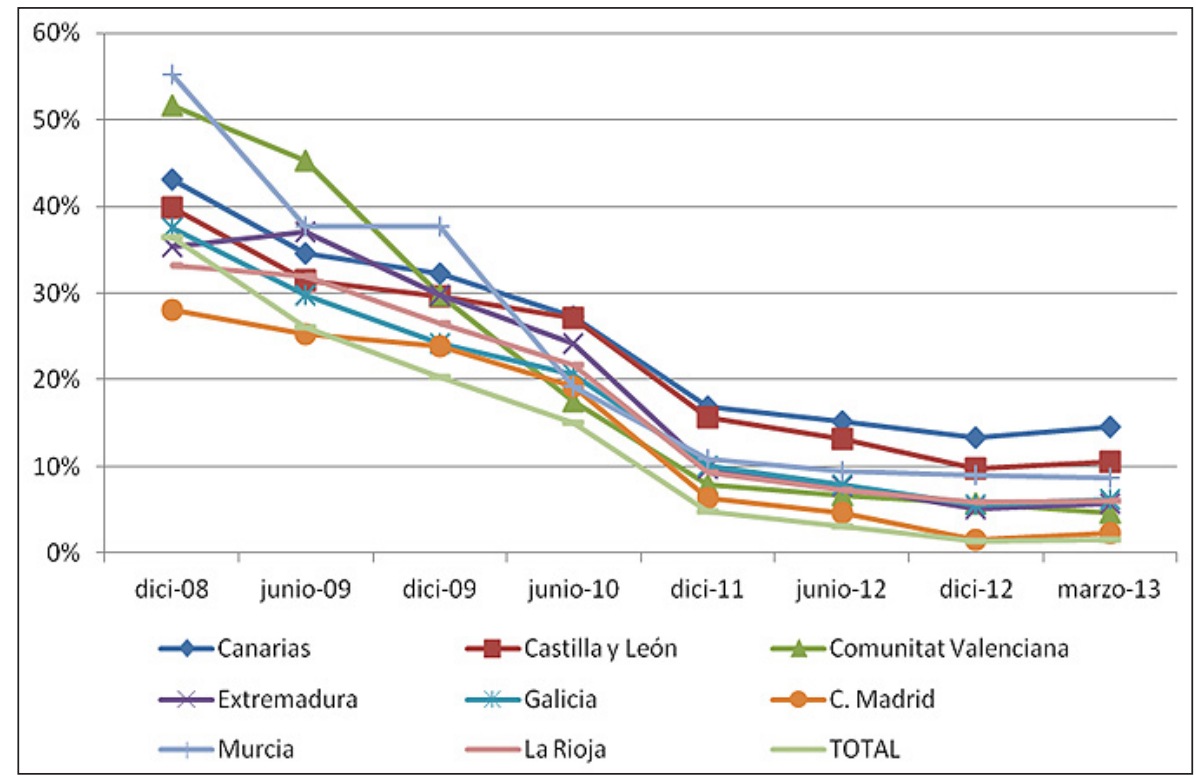

Fuente: Elaboración propia a partir de microdatos de EDAD2008 y datos estadísticos del SISAAD. 


\section{EL NUEVO BAREMO DE LA VIDA DIARIA}

El BVD aprobado en 2007 presentaba una serie de limitaciones que aconsejaban su modificación. Entre ellas destacaba la dificultad de captar adecuadamente la DIEM y los problemas cognitivos-conductuales, la necesidad de ponderar de forma diferente los apoyos en ABVD, así como la experiencia acumulada en los cuatro años de andadura del SAAD, que aconsejaban introducir mejoras en el proceso de valoración.

Como consecuencia de ello, en junio de 2011 se publicó un nuevo Baremo de dependencia. Cabe destacar entre las principales modificaciones introducidas la diferenciación en el no desempeño de la tarea, el ajuste conceptual de la definición de los tipos de apoyo, la simplificación de tareas objeto de valoración y la potenciación de los informes de salud y las pruebas objetivas en la valoración. La metodología de este trabajo no permite conocer cómo ha incidido el nuevo BVD en el número y distribución de los dependientes, salvo en algunas modificaciones puntuales, como el redondeo de la puntuación final al entero más cercano, o los cambios de la puntuación asignada en las actividades y tareas en que se descomponen.

Con las limitaciones apuntadas, cabe afirmar que el nuevo BVD no altera prácticamente el número absoluto de dependientes: 1.602.123 frente a 1.589.419. La única alteración significativa que se observa en la población teórica es la distribución según Grado, reduciéndose en un 2\% el Grado I con el nuevo BVD, e incrementándose aquellos con Grado III (tabla 5).

TABLA 5. COMPARACIÓN POBLACIÓN DEPENDIENTE SEGÚN BVD. POBLACIÓN TEÓRICA

\begin{tabular}{|l|l|l|r|r|r|r|}
\hline & \multicolumn{2}{|c|}{ BVD 2007 } & \multicolumn{2}{c|}{ BVD 2011 } & Dif. Absoluta & Dif. Porcentual \\
\hline Grado I & 728.154 & $45.4 \%$ & 688.369 & $43.3 \%$ & -39.785 & $-2.1 \%$ \\
\hline Grado II & 441.873 & $27.6 \%$ & 435.834 & $27.4 \%$ & -6.039 & $-0.2 \%$ \\
\hline Grado III & 432.096 & $27.0 \%$ & 465.219 & $29.3 \%$ & 33.123 & $2.3 \%$ \\
\hline
\end{tabular}

Fuente: Elaboración propia a partir de microdatos de EDAD2008.

Por CCAA, la implantación del nuevo BVD provoca que algunas CCAA (C.F. de Navarra, P. de Asturias, Cantabria y Canarias) vean reducida la población teórica con Grado III en mayor medida que la media para todo el Estado.

El nuevo BVD tiene un notable efecto en la distribución por grados según el lugar de residencia. En el caso de los dependientes en centros residenciales, el 41\% sería considerado como dependiente de Grado III (frente al 29\% del anterior BVD). Por el contrario, el volumen de dependientes de menor grado desciende del $43 \%$ al $29 \%$ en los centros.

\section{CONCLUSIONES}

La población teóricamente dependiente existente en España, siguiendo los criterios establecidos por el BVD, alcanzaba la cifra de 1.589.419 en 2008, volumen superior a las estimaciones efectuadas por el LB y la Memoria Económica de la LAPAD. Existe un volumen de población teórica no reconocida cifrada en 332.000 dependientes. Si bien la brecha existente se fue cerrando progresivamente hasta diciembre de 2010, si se consideran los grados y niveles en vigor, a partir de esa fecha se incrementa, como consecuencia de la reducción de los dependientes del SAAD.

Con referencia a diciembre de 2011 la práctica totalidad de las CCAA habían reconocido un volumen de dependientes inferior al estimado. En algunas de ellas (Comunitat Valenciana, Galicia, P. Asturias, y Canarias) la diferencia en infra-reconocimiento alcanzaba proporciones que oscilaban entre el $75 \%$ y el $104 \%$.

Ha existido una sobrerrepresentación de dependientes de mayor grado. En diciembre de 2011 la sobrerrepresentación afectaba a la práctica totalidad de las CCAA, aunque las diferencias eran acusadas. Canarias, Castilla y León, Murcia y Galicia presentaban valores porcentuales de exceso de población con Grado III comprendidos entre el $17 \%$ y $10 \%$. Esta sobrerrepresentación se ha reducido con el transcurso del tiempo, pasando del $36 \%$ en 2008, al 5\% en 2011 y al 2\% en 2012. Ello obedece a la paulatina reducción del porcentaje del Grado III sobre el total de dependientes del SAAD como consecuencia de la entrada en el sistema del resto de Grados y niveles. No obstante, en el momento presente (marzo de 2013), algunas CCAA mantienen el exceso de dependientes de mayor grado en relación a los estimados: Canarias (15\%), Castilla y León (11\%), Murcia (9\%), Extremadura y la Rioja (6\%) o la C. Valenciana (5\%).

La entrada en vigor del nuevo BVD no altera la cifra total de dependientes, si se consideran exclusivamente las modificaciones medibles a la vista de la metodología utilizada en el presente trabajo. Sí altera muy ligeramente su distribución, incrementando la población de Grado III en un $2 \%$. 
En todo caso, deben tenerse en cuenta las limitaciones que presenta la estimación de la población potencialmente dependiente a partir de los datos de la EDAD.

\section{BIBLIOGRAFÍA}

ADAY, L. y ANDERSEN, R. (1974), "A Theoretical Framework for the study of Access to Medical Care". Health Services Research. Vol 9-3.: 208-220. En línea: <http://www.ncbi.nlm.nih.gov/pmc/articles/PMC1071804/> (consulta: 15 marzo 2013).

AEVAL (2009), La participación de la Administración General del Estado en el Sistema para la Autonomía y Atención a la Dependencia. En línea: <www.aeval.es/comun/pdf/evaluaciones/E13add.pdf'> (consulta: 15 marzo 2013).

ALBARRÁN, I. y P. ALONSO (2009), "La población dependiente en España: estimación del número y coste global asociado a su cuidado”, Estudios de Economía. Vo. 36.:127-163. DOI: 10.4067/SO718-52862009000200001.

ANDERSEN, R. (1995), "Revisting the Behavioral Model and Access to Medical Care: Does it Matter?". Journal of Health and Social Behaviour. Vol. 36:1-10. DOI: 10.1186/1750-4732-2-12.

Asociación ESTATAL DE DIRECTORAS Y GERENTES DE SERVICIOS SOCIALES (2011), Evaluación del SAAD después de cuatro años. En línea: < http://www.feafes.org/publicaciones/VIDictamenObservatorio.pdf > (consulta: 15 marzo 2013).

BarriGa Martín, L., Brezmes Nieto, Ma Jesús y García Herrero, G. A. (2013), Informe sobre el desarrollo y evaluación territorial de la LAPAD. Asociación Estatal de Directores y Gerente en Servicios Sociales. X Dictámen del Observatorio de la dependencia. En línea: < http://apeto.com/files/Dictamen_Obs_Dependencia.pdf > (consulta: 15 marzo 2013).

CASADO, D. (2007), Efectos y abordajes de la dependencia: un análisis económico. Ed. Masson.

CROSBY, G. y A. CLARK (2009), Ageism and Age Discrimination in Social Care in the United Kingdom. A Review from the Literature. Centre for Policy on Ageing. En línea: <http://www.cpa.org.uk/information/reviews/CPA-\%20 ageism_and_age_discrimination_in_social_care-report.pdf > (consulta: 15 marzo 2013).

GonzÁlez Rodrícuez, R.; GANDoy CReGo, M. y Clemente Díaz, M. (2012), "Fiabilidad del instrumento para valorar la situación de dependencia en España”. Revista de Servicios Sociales y Política Social. № 99.: 99-108. Madrid.

GRUPO DE EXPERTOS (2009), Informe final del grupo de expertos para la evaluación del desarrollo y efectiva aplicación de la LAPAD. En línea: <http://www.imsersomayores.csic.es/documentos/documentos/comisionexpertosinforme-01.pdf> (consulta: 15 marzo 2013).

IMSERSO:

- (2005), Atención a las personas en situación de dependencia en España. Libro Blanco. En línea: <http://www.imsersomayores.csic.es/documentos/documentos/mtas-libroblancodependencia-01.pdf > (consulta: 15 marzo 2013).

- (2007), Manual del uso para el empleo del baremo de valoración de la dependencia. Dirigido a profesionales valoradores. En línea: <http://www.femp.es/files/566-29-archivo/manualusoBVD.pdf> (consulta: 15 marzo 2013).

INSTITUTO DE ESTUDIOS FISCALES (2006), El papel de los registros administrativos en relación con el análisis social y económico y el desarrollo del sistema estadístico nacional.

JACOBZONE, S. (1999), "Ageing and Care for Frail Elderly Persons: an Overview of International Perspectives". OCDE. Labour Market and Social Policy. Occasional Papers n 38. DOI: $10.1787 / 313777154147$.

JACOBZONE, S.; CAMBois,E.; ChAPLAIN, E. y RoBine, J.M. (1998)," The health of older persons in OECD countries: is it improving fast enough to compensate for population ageing?" OCDE. Labour Market and Social Policy. Occasional Papers $\mathrm{n}^{\circ}$ 37. DOI:10.1787/066187831020.

KAHALE CARRILLO, D.J. (2009), La cobertura de la situación de dependencia. Fundación alternativas. 2009. En línea: <http://www.falternativas.org/estudios-de-progreso/documentos/documentos-de-trabajo/la-cobertura-dela-situacion-de-dependencia> (consulta: 15 marzo 2013).

MANTON, K.G.; CORDER, L.; STALLARD,E. (1997), "Crhonic disability trends in elderly United Statespopulations: $1982-$ 1994". Proceedings of the National Academy of Sciencies USA. 1997. Vol. 6. :2593-2598. DOI: 10.1073/pnas.94.6.2593.

MARBÁN GALLEGO, V. (2012), "Actores sociales y desarrollo de la Ley de dependencia en España”. Revista Internacional de Sociología . Vol.70, nº 2, Mayo-Agosto: 375-398. DOI: 10.3989/ris.2010.06.29. 
Ministerio de TRABAjo y AsUntos SOCIALES. (2006), Memoria del Análisis de Impacto normativo, económico, de género e igualdad de oportunidades, no discriminación y accesibilidad universal. En línea: <http://www.inforesidencias.com/docs_no_pago/memoria_ley_dependencia.pdf> (consulta: 15 marzo 2013).

MiniSTERIO DE SANIDAD, PolítICA SOCIAL E IGUALDAD (2011), Informe del Gobierno para la evaluación de la LAPAD. Noviembre de 2011. En línea: <http://www.dependencia.imserso.es/InterPresent1/groups/imserso/documents/binario/ie_2011_informeevaluacion.pdf> (consulta: 15 marzo 2013).

Morán AlÁEZ, E. y RodríGuez CABRERO, G. (2005), La población dependiente en España en 1999 y proyecciones a 2005 y 2015 (mímeo). Madrid. DOI: 10.4067/S0718-52862009000200001.

PALACIOS, E. y ABELLÁN, A. (2007), “Diferentes estimaciones de la discapacidad y la dependencia en España”. Madrid, Portal Mayores, Informes, $n^{\circ}$ 56. En línea: <http://www.imsersomayores.csic.es/documentos/documentos/ abellan-estimaciones-11.pdf> (consulta: 15 marzo 2013).

RAZAVI, Tiffani (2001), "Self-report measures: an overview of concerns and limitations of questionnaire use in occupational stress research". Southampton, UK, University of Southampton. Discussion Papers in Accounting and Management Science. En línea: <http://eprints.soton.ac.uk/35712/1/01-175.pdf> (consulta: 15 marzo 2013).

Rodrícuez CABrero, G. (2004), Protección social de la dependencia en España. Fundación Alternativas. Documento de trabajo 44/2004. En línea: <http://www.falternativas.org/laboratorio/documentos/documentos-detrabajo/proteccion-social-de-la-dependencia-en-espana> (consulta: 15 marzo 2013).

RodríGuez CASTEDO, A. y JIMÉNEZ LARA, A. (2010), La atención a la dependencia y el empleo. Fundación Alternativas. Documento de trabajo 159/2010. En línea: <http://www.falternativas.org/laboratorio/documentos/documentos-de-trabajo/la-atencion-a-la-dependencia-y-el-empleo-potencial-de-creacion-de-empleo-y-otros-efectos-economicos-de-la-ley-de-promocion-de-la-autonomia-personal-y-atencion-a-las-personas-en-situacion-de-dependencia> (consulta: 15 marzo 2013).

RodríGuez CABRERO, G. y MONTSERRAT, J. (2002), Modelos de atención sociosanitaria. Una aproximación a los costes de la dependencia. IMSERSO. En línea: <http://ccp.ucr.ac.cr/creles/pdf/monserrat-modelos-01.pdf> (consulta: 15 marzo 2013).

Rodríguez, G.; CASAdo, D.; Jiménez, A.; MontSerrat, J.; Morán, E. y VilÁ, A. (2005), Un modelo de gestión de la dependencia aplicable a España. Universidad Alcalá de Henares.

SALVÀ, A.; RoJANO, X. y RIVERO, T. (2006), "Las situaciones de dependencia. Su valoración, los baremos y su aplicación”. Documentación Administrativa. N 276-277.

SEVERENS, J.L; MULDER, J.; RJF LAHEIJ et al. (2000), "Precision and accuracy in measuring absence from work as a basis for calculating productivity cost in the Netherlands". Social Science and Medicine 2000. Vol. 51.: 243-249. DOI: 10.1016/S0277-9536(99)00452-9.

SPECTOR, P. E. (1994), “Using Self-Report Questionnaires in OB Research: A comment on the use of a controversial method”. Journal Of Organizational Behavior. Vo 15, No. 5 Septiembre 1994.: 385-392. En línea: < http:// myweb.usf.edu/ jdorio/ORM/Spector,\%20P.\%20E.\%20(1994)..pdf> (consulta: 15 marzo 2013).

VILAPLANA, C. (2010), “Estimación de la dependencia en España a partir de la EDAD 2008”. Hacienda Pública Española. N 194.: 125-175. En línea: <http://www.ief.es/documentos/recursos/publicaciones/revistas/hac_pub/194_ Art5.pdf> (consulta: 15 marzo 2013). 


\section{ANEXO I}

TABLA 6. ACtiVIDAdES, TAREAS DEL BVD y CORRESPONDENCIA CON LOS ÍTEMS DE LA ENCUESTA EDAD2008. CRITERIOS SEGUIDOS EN LA ESTIMACIÓN

\begin{tabular}{|c|c|c|}
\hline ACTIVIDADES / TAREAS & $\begin{array}{l}\text { ITEMS } \\
\text { ENCUESTA }\end{array}$ & CRITERIO EMPLEADO \\
\hline \multicolumn{3}{|c|}{$\begin{array}{l}\text { Abrir botellas y latas; cortar o partir la carne en trozos; usar cubiertos para llevar la comida a la boca; sujetar el recipiente } \\
\text { de bebida; acercarse el recipiente de bebida a la boca; sorber las bebidas }\end{array}$} \\
\hline COMER Y BEBER & 33.1 & $\begin{array}{l}\text { Si tiene dificultad, se le asigna la puntuación total del } \\
\text { grupo de actividades de comer y beber }\end{array}$ \\
\hline Acudir a un lugar adecuado & \multirow{4}{*}{29.1 y 30.1} & \multirow{4}{*}{$\begin{array}{l}\text { La asociación entre presentar dificultades en tareas de } \\
\text { continencia de la micción o la defecación es muy elevada } \\
\text { (el valor de Coeficiente Phi y V de Cramer es 0.936). Por } \\
\text { ello, si el individuo encuestado manifiesta dificultades en } \\
\text { cualquiera de ellas (ítems } 29.1 \text { y } 30.1 \text { ), se considera que no } \\
\text { puede efectuar las tareas y se le asigna la correspondien- } \\
\text { te puntuación. }\end{array}$} \\
\hline Manipular la ropa & & \\
\hline Adoptar y abandonar la postura adecuada & & \\
\hline Limpiarse & & \\
\hline Continencia micción & 29.1 & $\begin{array}{l}\text { Si tiene dificultad, se le asigna la puntuación correspon- } \\
\text { diente a esta tarea }\end{array}$ \\
\hline Continencia defecación & 30.1 & $\begin{array}{l}\text { Si tiene dificultad, se le asigna la puntuación correspon- } \\
\text { diente a esta tarea }\end{array}$ \\
\hline REGULACIÓN DE LA MICCIÓN/DEFECACIÓN & & $\begin{array}{l}\text { La puntuación total correspondiente al grupo de activi- } \\
\text { dades es el sumatorio de las puntuaciones específicas de } \\
\text { las tareas }\end{array}$ \\
\hline \multicolumn{2}{|c|}{$\begin{array}{l}\text { Lavarse las manos; lavarse la cara; lavarse la parte inferior del } \\
\text { cuerpo; lavarse la parte superior del cuerpo }\end{array}$} & \\
\hline LAVARSE & 27.1. & $\begin{array}{l}\text { Si tiene dificultad, se le asigna la puntuación total del } \\
\text { grupo de actividades de comer y beber }\end{array}$ \\
\hline Peinarse; cortarse las uñas & 28.1 & $\begin{array}{l}\text { Si tiene dificultad, se le asigna la puntuación correspon- } \\
\text { diente a ambas tareas }\end{array}$ \\
\hline Lavarse el pelo; lavarse los dientes & 27.1 & $\begin{array}{l}\text { Si tiene dificultad, se le asigna la puntuación correspon- } \\
\text { diente a ambas tareas }\end{array}$ \\
\hline OTROS CUIDADOS CORPORALES & & $\begin{array}{l}\text { La puntuación total correspondiente al grupo de activi- } \\
\text { dades es el sumatorio de las puntuaciones específicas de } \\
\text { las tareas }\end{array}$ \\
\hline \multicolumn{2}{|c|}{$\begin{array}{l}\text { Calzarse; abrocharse botones; vestirse prendas de la parte infe- } \\
\text { rior del cuerpo; vestirse prendas de la parte superior del cuerpo }\end{array}$} & \\
\hline VESTIRSE & 32.1. & $\begin{array}{l}\text { Si tiene dificultad, se le asigna la puntuación total del } \\
\text { grupo de actividades de comer y beber }\end{array}$ \\
\hline Aplicarse medidas terapéuticas recomendadas & 34.1. & $\begin{array}{l}\text { Si tiene dificultad, se le asigna la puntuación correspon- } \\
\text { diente a esta tarea }\end{array}$ \\
\hline Evitar riesgos dentro del domicilio & \multirow{2}{*}{35.1.} & \multirow{2}{*}{$\begin{array}{l}\text { Si tiene dificultad, se le asigna la puntuación correspon- } \\
\text { diente a ambas tareas }\end{array}$} \\
\hline Evitar riesgos fuera del domicilio & & \\
\hline Pedir ayuda ante una urgencia & 8.1. y 40.1 & $\begin{array}{l}\text { Si tiene dificultad en cualquiera de las preguntas, se le } \\
\text { asigna la puntuación correspondiente a esta tarea }\end{array}$ \\
\hline $\begin{array}{l}\text { Evitar riesgos dentro del domicilio; evitar ries- } \\
\text { gos fuera del domicilio; pedir ayuda ante una } \\
\text { urgencia }\end{array}$ & 35.1. & $\begin{array}{l}\text { Si tiene dificultad, se le asigna la puntuación correspon- } \\
\text { diente a las tres tareas }\end{array}$ \\
\hline MANTENIMIENTO DE LA SALUD & & $\begin{array}{l}\text { La puntuación total correspondiente al grupo de activi- } \\
\text { dades es el sumatorio de las puntuaciones específicas de } \\
\text { las tareas }\end{array}$ \\
\hline \multicolumn{2}{|c|}{$\begin{array}{l}\text { Sentarse; tumbarse; ponerse de pie; transferir mientras senta- } \\
\text { do; transferir mientras acostado }\end{array}$} & \\
\hline
\end{tabular}




\begin{tabular}{|c|c|c|}
\hline TRANSFERENCIAS CORPORALES & 18.1. & $\begin{array}{l}\text { Se ha optado por no considerar para la valoración de la } \\
\text { actividad el ítem } 19.1 \text { dificultad para mantener el cuerpo } \\
\text { en la misma posición, toda vez que no implica transfe- } \\
\text { rencia. Si el encuestado tiene dificultad, se le asigna la } \\
\text { puntuación total correspondiente al grupo de actividades } \\
\text { de transferencias corporales }\end{array}$ \\
\hline \multicolumn{3}{|c|}{$\begin{array}{l}\text { Realizar desplaza. vinculados al autocuidado; realizar desplaza. no vinculados al autocuidado; acceder a todos los elemen- } \\
\text { tos comunes de las habitaciones; acceder a todas las estancias comunes de la vivienda habitual }\end{array}$} \\
\hline DESPLAZARSE DENTRO DEL HOGAR & 20.1. & $\begin{array}{l}\text { Si tiene dificultad, se le asigna la puntuación total corres- } \\
\text { pondiente al grupo de actividades de desplazamiento } \\
\text { dentro del hogar }\end{array}$ \\
\hline $\begin{array}{l}\text { Acceder al exterior del edificio; desplazarse } \\
\text { alrededor del edificio; realizar desplazamientos } \\
\text { cercanos }\end{array}$ & 21.1. & $\begin{array}{l}\text { Si tiene dificultad, se le asigna la puntuación correspon- } \\
\text { diente a las tres tareas }\end{array}$ \\
\hline Realizar desplazamientos lejanos & \multirow[b]{2}{*}{22.1.} & \multirow{2}{*}{$\begin{array}{l}\text { A los individuos con edad superior a los } 18 \text { años se les } \\
\text { asigna un } 50 \% \text { de la puntuación específica de las dos } \\
\text { tareas a cada ítem de la encuesta. En el caso de los indivi- } \\
\text { duos con edad inferior, dado que tan sólo pueden viajar } \\
\text { como pasajeros, se les asigna el } 100 \% \text { de ambas puntua- } \\
\text { ciones en el ítem } 22.1\end{array}$} \\
\hline Utilizar medios de transporte & & \\
\hline DESPLAZARSE FUERA DEL HOGAR & & $\begin{array}{l}\text { La puntuación total correspondiente al grupo de activi- } \\
\text { dades es el sumatorio de las puntuaciones específicas de } \\
\text { las tareas }\end{array}$ \\
\hline Preparar comidas & 37.1. & $\begin{array}{l}\text { Si tiene dificultad, se le asigna la puntuación correspon- } \\
\text { diente a esta tarea }\end{array}$ \\
\hline Hacer la compra & 36.1 & $\begin{array}{l}\text { Si tiene dificultad, se le asigna la puntuación correspon- } \\
\text { diente a esta tarea }\end{array}$ \\
\hline $\begin{array}{l}\text { Limpiar y cuidar de la vivienda; lavar y cuidar la } \\
\text { ropa }\end{array}$ & 38.1. & $\begin{array}{l}\text { Si tiene dificultad, se le asigna la puntuación correspon- } \\
\text { diente a ambas tareas }\end{array}$ \\
\hline TAREAS DOMÉSTICAS & & $\begin{array}{l}\text { La puntuación total correspondiente al grupo de activi- } \\
\text { dades es el sumatorio de las puntuaciones específicas de } \\
\text { las tareas }\end{array}$ \\
\hline $\begin{array}{l}\text { Actividades de autocuidado; actividades de } \\
\text { movilidad; tareas domésticas }\end{array}$ & 15.1.,44.1. & $\begin{array}{l}\text { Si tiene dificultad, se le asigna la puntuación correspon- } \\
\text { diente a ambas tareas }\end{array}$ \\
\hline Relaciones interpersonales & $\begin{array}{l}39.1,40.1 \\
41.1,42.1 \\
43.1,44.1\end{array}$ & $\begin{array}{l}\text { A los individuos que responden afirmativamente a cada } \\
\text { una de las preguntas, se le asigna un } 20 \% \text { de la puntuación } \\
\text { concreta correspondiente }\end{array}$ \\
\hline Gestión del dinero & \multirow{2}{*}{ 44.1. } & \multirow{2}{*}{$\begin{array}{l}\text { Si tiene dificultad, se le asigna la puntuación correspon- } \\
\text { diente a ambas tareas }\end{array}$} \\
\hline Uso de servicios a disposición del público & & \\
\hline TOMAR DECISIONES & & $\begin{array}{l}\text { La puntuación total correspondiente al grupo de activi- } \\
\text { dades es el sumatorio de las puntuaciones específicas de } \\
\text { las tareas }\end{array}$ \\
\hline
\end{tabular}

Fuente: Elaboración propia 
TABLA 7. TAREAS CONSIDERADAS PARA LA ESTIMACIÓN DE DI/EM.ÍTEMS DE LA ENCUESTA EDAD2008

\begin{tabular}{|c|c|c|}
\hline Bloque & Tareas/actividades & Ponderación \\
\hline \multirow{7}{*}{$\begin{array}{l}\text { Afectaciones en su capa- } \\
\text { cidad perceptivo }\end{array}$} & 1.1 Es ciego/a o sólo distingue luz y oscuridad & \multirow{2}{*}{$\begin{array}{l}\text { 2(o } 3 \text {, si existe enfer- } \\
\text { medad mental) }\end{array}$} \\
\hline & 5.1 Es sordo/a total & \\
\hline & $\begin{array}{l}\text { 3.1 Dificultad importante para ver la cara de alguien al otro lado de la } \\
\text { calle ( } 4 \text { metros) aunque lleve gafas o lentillas }\end{array}$ & $\begin{array}{l}\text { 1(o 2, si existe enfer- } \\
\text { medad mental ) }\end{array}$ \\
\hline & $\begin{array}{l}\text { 2.1 Dificultad importante para ver la letra de un periódico aunque lleve } \\
\text { gafas o lentillas }\end{array}$ & \multirow{4}{*}{$\begin{array}{l}0.5 \text { ( } 01 \text {, si existe enfer- } \\
\text { medad mental) }\end{array}$} \\
\hline & $\begin{array}{l}\text { 4.1 Alguna otra dificultad importante de visión aunque lleve gafas o } \\
\text { lentillas (diferenciación de colores, visión nocturna, etc.). }\end{array}$ & \\
\hline & $\begin{array}{l}\text { 6.1 Dificultad importante para oír una alarma, una sirena u otros soni- } \\
\text { dos fuertes sin audífono u otro tipo de ayuda técnica externa }\end{array}$ & \\
\hline & $\begin{array}{l}\text { 7.1 Dificultad importante para oír lo que se dice en una conversación } \\
\text { con varias personas sin audífono u otro tipo de ayuda técnica externa }\end{array}$ & \\
\hline \multirow{5}{*}{$\begin{array}{l}\text { Dificultad de comunica- } \\
\text { ción }\end{array}$} & $\begin{array}{l}\text { 8.1 Hablar de manera comprensible o decir frases con sentido sin } \\
\text { ayudas técnicas externas }\end{array}$ & \multirow{4}{*}{$\begin{array}{l}\text { 1(o 2, si existe enfer- } \\
\text { medad mental) }\end{array}$} \\
\hline & $\begin{array}{l}\text { 9.1 Dificultad importante para comprender el significado de lo que le } \\
\text { dicen otras personas sin ayudas personales }\end{array}$ & \\
\hline & $\begin{array}{l}\text { 10.1 Dificultad importante para comprender un texto escrito o expre- } \\
\text { sarse a través del mismo }\end{array}$ & \\
\hline & $\begin{array}{l}\text { 12.1 Dificultad importante para mantener una conversación a través } \\
\text { del lenguaje hablado, escrito y otro tipo de lenguaje }\end{array}$ & \\
\hline & $\begin{array}{l}\text { 11.1 Dificultad importante para comprender gestos, símbolos, dibujos, } \\
\text { sonidos y expresar a través de ellos }\end{array}$ & $\begin{array}{l}\text { 2(o } 3 \text {, si existe enfer- } \\
\text { medad mental) }\end{array}$ \\
\hline \multirow{4}{*}{$\begin{array}{l}\text { Aprendizaje y aplicación } \\
\text { del conocimiento y desa- } \\
\text { rrollo de tareas }\end{array}$} & $\begin{array}{l}\text { 14.1 Debido a un problema mental, dificultad importante para prestar } \\
\text { atención con la mirada o mantener la atención con el oído }\end{array}$ & \multirow{4}{*}{$\begin{array}{l}\text { 2(o } 3 \text {, si existe enfer- } \\
\text { medad mental) }\end{array}$} \\
\hline & $\begin{array}{l}\text { 15.1 Debido a un problema mental, dificultad importante para apren- } \\
\text { der a hacer cosas sencillas como copiar, leer, escribir, sumar o restar, } \\
\text { o aprender a manejar utensilios de uso cotidiano }\end{array}$ & \\
\hline & $\begin{array}{l}\text { 16.1 Debido a un problema mental, dificultad importante para llevar a } \\
\text { cabo tareas sencillas sin ayudas y sin supervisión }\end{array}$ & \\
\hline & $\begin{array}{l}\text { 17.1 Debido a un problema mental, dificultad importante para llevar a } \\
\text { cabo tareas complejas sin ayudas y sin supervisión }\end{array}$ & \\
\hline
\end{tabular}

Fuente: Elaboración propia. 